\title{
Molecular characteristics and predictors of mortality among Gram-positive bacteria isolated from bloodstream infections in critically ill patients during a 5-year period (2012-2016)
}

\author{
Matthaios Papadimitriou-Olivgeris ${ }^{1,5} \cdot$ Fevronia Kolonitsiou $^{2} \cdot$ Vasileios Karamouzos $^{3} \cdot$ Katerina Tsilipounidaki $^{4}$. \\ Alexandra Nikolopoulou ${ }^{3} \cdot$ Fotini Fligou $^{3} \cdot$ Markos Marangos $^{1} \cdot$ Efthimia Petinaki $^{4} \cdot$ Iris Spiliopoulou $^{2}$
}

Received: 17 November 2019 / Accepted: 17 December 2019 / Published online: 2 January 2020

(C) Springer-Verlag GmbH Germany, part of Springer Nature 2020

\begin{abstract}
To identify the molecular characteristics of Gram-positive cocci isolated from blood cultures and clinical outcome among critically ill patients. This retrospective study was conducted in the general intensive care unit of the University General Hospital of Patras, Greece, during a 5-year period (2012-2016). All adult patients with a Gram-positive BSI were included. PCR was applied to identify mecA gene (staphylococci); vanA, vanB, and vanC genes (enterococci). Linezolid-resistant S. epidermidis, MRSA, and VRE were further typed by multilocus sequence typing. Mutations in region V of 23S rDNA and ribosomal protein L4were investigated by PCR and sequencing analysis. The presence of the $c f r$ gene was tested by PCR. In total, 141 Gram-positive BSIs were included. Coagulase-negative staphylococci predominated $(n=69 ; 65$ methicillin-resistant, 23 linezolid-resistant carrying both C2534T and T2504A mutations and belonging to the ST22 clone), followed by enterococci $(n=$ 46; 11 vancomycin-resistant carrying vanA gene, classified into four clones), S. aureus ( $n=22 ; 10$ methicillin-resistant, classified into three clones) and streptococci $(n=4)$. The most common type of infection was catheter-related $(66 ; 46.8 \%)$, followed by primary BSI $(28 ; 19.9 \%)$. Overall 14-day fatality was $24.8 \%$. Multivariate analysis revealed septic shock as independent predictor of fatality, while appropriate empiric antimicrobial treatment and catheter-related BSI were identified as a predictor of good prognosis. Even though most of Gram-positive cocci were multidrug-resistant, fatality rate was low, associated with catheter-related BSIs. Among CNS, LR isolates represented one-third of BSIs due to the dissemination of ST22 S. epidermidis propagated by utilization of linezolid.
\end{abstract}

Keywords Methicillin-resistant S. aureus (MRSA) · Coagulase-negative staphylococci · Vancomycin-resistant enterococci $($ VRE) $\cdot$ Linezolid resistance $\cdot$ Septic shock

Iris Spiliopoulou

spiliopl@upatras.gr

1 Department of Internal Medicine, Division of Infectious Diseases, School of Medicine, University of Patras, Patras, Greece

2 Department of Microbiology, School of Medicine, University of Patras, Campus, 26504, Rion, Patras, Greece

3 Anesthesiology and Critical Care Medicine, School of Medicine, University of Patras, Patras, Greece

4 Department of Microbiology, School of Medicine, University of Thessaly, Larissa, Greece

5 Present address: Department of Infectious Diseases, University Hospital of Lausanne, Lausanne, Switzerland

\section{Introduction}

Bloodstream infections (BSIs) are a common occurrence among critically ill patients, being associated with increased morbidity and mortality [1-3]. Even though Gram-negative bacteria predominate among aforementioned population, Gram-positive cocci provoke a considerable proportion of BSIs especially catheter-related (CR-BSIs) [4]. According to EPIC II, among Gram-positive cocci, staphylococci predominated, followed by enterococci and streptococci [3].

Due to widespread use of antibiotics, in addition to failing infection control practices, multidrug-resistant Gram-positive cocci are endemic in many countries, including Greece [2, 5, 6]. Staphylococcus aureus represents the most virulent among Gram-positive cocci and accounts for 9\% of BSI in Greece, of which more than $40 \%$ were caused by strains resistant to 
methicillin (MRSA) [5]. MRSA incidence progressively declined from 2000 to 2015 [7]. Occurrence of vancomycin resistance among enterococci declines in Greece, representing $7.5-8.5 \%$ of isolates in the UGHP during the study period (personal data). According to the European Center for Disease Prevention and Control, vancomycin resistance among Enterococcus faecalis decreased from 5.2\% in 2006 to $0 \%$ in 2017 ; vancomycin resistance among $E$. faecium decreased during the same period from 42.5 to $30.8 \%$ [8]. The high prevalence of multidrug-resistant Gram-positive cocci has led to increased use of antibiotics with enhanced antiGram-positive activity, such as glycopeptides, and newer ones like linezolid and daptomycin $[1,9]$. The use of linezolid contributed to the rise and dissemination of strains resistant to that antibiotic, especially in CNS [10-13].

We performed a retrospective study in order to elucidate the epidemiology and mortality of BSIs due to Gram-positive cocci among critically ill patients.

Methods This retrospective study was conducted in the general intensive care unit (ICU) of the University General Hospital of Patras, Greece, during a 5-year period (2012 to 2016). The study was approved by the Bioethics' Committee of the University General Hospital of Patras (No 434).

All adult patients ( $\geq 18$ years old) with positive blood cultures by Gram-positive bacteria were eligible. Isolation of a common commensal organism from blood cultures, such as Bacillus spp., coagulase-negative staphylococci (CNS), Corynebacterium spp., Micrococcus spp., and Cutibacterium spp., was characterized as true BSI if the pathogen was isolated from at least two blood culture sets, as described by US Centers for Disease Control and Prevention (CDC) guidelines; for all other pathogens, only one positive blood culture associated with clinical signs of infection were sufficient for the identification of BSI. The CDC definition was used to characterize BSI as primary or secondary (urinary, respiratory, catheter-related, abdominal, skin and soft tissue infections, endocarditis, meningitis) [14]. Infection was categorized as sepsis or septic shock according to new sepsis definition. The date of collection of the first positive blood culture was defined as infection onset [15]. Appropriate antibiotic treatment was defined as one that included an antimicrobial agent with in vitro activity against the infecting isolates, initiated within $72 \mathrm{~h}$ from the onset of infection, at an adequate dosage.

Antibiotic susceptibility testing was performed by the agar disk diffusion method and the Etest according to EUCAST guidelines. PCR was applied to detect mecA gene in phenotypically cefoxitin-resistant staphylococci; $\operatorname{van} A, \operatorname{van} B$, and van $C$ genes in phenotypically vancomycin-resistant enterococci (VRE), and $c f r$ in linezolid non-susceptible CNS [16-18]. Mutations in region V of 23S rDNA were investigated by PCR and sequencing analysis [19]. Sequence data were analyzed using Chromas (www.technelysium.com.au/ chromas.html). The possible presence of mutations in ribosomal protein L4 was investigated by PCR followed by sequence analysis [20]. Linezolid-resistant $S$. epidermidis, MRSA and vancomycin-resistant E. faecium and E. faecalis (VRE) were further typed by multilocus sequence typing (http://www.mlst.net).

ICU's computerized database (Criticus TM, University of Patras, Greece) and patients' chart reviews were used in order to collect epidemiologic data. Parameters assessed included demographic characteristics (age, sex), co-morbidities, severity scores of illness on admission and upon onset of infection (SAPS II (Simplified Acute Physiology Score II) and SOFA (Sequential Organ Failure Assessment) scores), prior surgery, length of hospitalization, type of antibiotic administration, corticosteroid administration, and enteral or parenteral nutrition.

SPSS version 23.0 (SPSS, Chicago, IL) was used for data analyses. Categorical variables were analyzed by using the Fisher exact test and continuous variables with MannWhitney $U$ test. Multiple logistic regression analysis was performed. Factors contributing to multicollinearity were excluded from the multivariate analysis. Odds ratios (ORs) and 95\% confidence intervals (CIs) were calculated to evaluate the strength of any association. All statistic tests were 2-tailed and $P<0.05$ was considered statistically significant.

\section{Results}

Among the 1665 patients admitted to ICU during the study period, 575 episodes of BSI (from 403 patients) were recorded from which 141 were due to Gram-positive bacteraemia (129 patients), accounting for an incidence of 8.3 Gram-positive BSIs per 1000 patient-days. The most common type of infection was catheter-related $(66 ; 46.8 \%)$, followed by primary BSI $(28 ; 19.9 \%)$, urinary tract infections $(16 ; 11.3 \%)$, abdominal infection $(12 ; 8.5 \%)$, and ventilator-associated pneumonia $(10 ; 7.1 \%)$ (Table 1). Coagulase negative staphylococci (CNS) predominated ( $n=69 ; 63 \mathrm{~S}$. epidermidis, two S. haemolyticus, two $S$. lugdunensis, one $S$. capitis, and one S. hominis; 65 methicillin-resistant, 23 linezolid-resistant), followed by enterococci $(n=46 ; 11 \mathrm{VRE}), S$. aureus $(n=22$; 10 methicillin-resistant carrying mecA gene, MRSA), and streptococci ( $n=4$; two $S$. agalactiae, one $S$. gallolyticus, one $S$. mitis). All 23 coagulase-negative staphylococci that showed linezolid MIC $>256 \mathrm{mg} / \mathrm{l}$, were $S$. epidermidis, carried both $\mathrm{C} 2534 \mathrm{~T}$ and $\mathrm{T} 2504 \mathrm{~A}$ mutations and belonged to the ST22 clone. None of them carried the $c$ fr gene or any mutation in the L4 ribosomal protein gene. Among the $11 \mathrm{VRE}$, eight were $E$. faecium carrying the vanA gene and belonging to ST117 $(n=4), \operatorname{ST} 17(n=3)$, and ST203 $(n=1)$, two were E. gallinarum, vanC-positive, and one E. faecalis vanA-positive belonging to ST28. MRSA belonged to ST80 $(n=4)$, ST30 $(n=4)$, and ST239 $(n=2)$. Overall 14-day fatality was 
Table 1 Univariate analyses for predictors of fatality in patients with bacteraemia due to Gram-positive cocci

\begin{tabular}{|c|c|c|c|c|c|}
\hline \multirow[t]{2}{*}{ Characteristics } & \multicolumn{3}{|l|}{ Univariate analysis } & \multicolumn{2}{|c|}{ Multivariate analysis } \\
\hline & Survivors $(n=106)$ & Non-survivors $(n=35)$ & $P$ & $P$ & OR $(95 \% \mathrm{CI})$ \\
\hline \multicolumn{6}{|l|}{ Demographics } \\
\hline Age (years) & $55.3 \pm 17.9$ & $59.8 \pm 17.6$ & 0.240 & & \\
\hline Male gender & $81(76.4 \%)$ & $25(71.4 \%)$ & 0.652 & & \\
\hline \multicolumn{6}{|l|}{ Chronic diseases } \\
\hline Diabetes mellitus & $9(8.5 \%)$ & $5(14.3 \%)$ & 0.336 & & \\
\hline Chronic obstructive pulmonary disease & $4(3.8 \%)$ & $5(14.3 \%)$ & 0.042 & - & - \\
\hline Chronic heart failure & $7(6.6 \%)$ & $3(8.6 \%)$ & 0.709 & & \\
\hline Chronic kidney disease & $4(3.8 \%)$ & $0(0.0 \%)$ & 0.572 & & \\
\hline Malignancy (solid organ or hematologic) & $8(7.5 \%)$ & $2(5.7 \%)$ & 1.000 & & \\
\hline Immunosuppression & $6(5.7 \%)$ & $1(2.9 \%)$ & 0.681 & & \\
\hline Obesity & $30(28.3 \%)$ & $8(22.9 \%)$ & 0.662 & & \\
\hline Charlson comorbidity index & $3.1 \pm 2.9$ & $3.4 \pm 2.9$ & 0.476 & & \\
\hline \multicolumn{6}{|l|}{ Admission data } \\
\hline SAPS II upon admission & $36.1 \pm 10.7$ & $41.9 \pm 14.4$ & 0.099 & & \\
\hline SOFA score upon admission & $8.2 \pm 3.1$ & $9.7 \pm 3.7$ & 0.035 & & \\
\hline Prior surgery & $52(49.1 \%)$ & $11(31.4 \%)$ & 0.080 & & \\
\hline \multicolumn{6}{|l|}{ Infection data } \\
\hline Days at risk & $11.5 \pm 10.2$ & $11.2 \pm 9.9$ & 0.879 & & \\
\hline Septic shock & $29(27.4 \%)$ & $28(80.0 \%)$ & $<0.001$ & 0.039 & $4.0(1.1-10.9)$ \\
\hline Noradrenaline dose $(\mu \mathrm{g} / \mathrm{kg} / \mathrm{min})$ & $5.6 \pm 12.5$ & $30.5 \pm 22.3$ & $<0.001$ & & \\
\hline \multicolumn{6}{|l|}{ Source of infection } \\
\hline Catheter-related bateraemia & $58(54.7 \%)$ & $8(22.9 \%)$ & 0.002 & 0.024 & $0.28(0.09-0.85)$ \\
\hline Abdominal infection & $9(8.5 \%)$ & $3(8.6 \%)$ & 1.000 & & \\
\hline Urinary tract infection & $13(12.3 \%)$ & $3(8.6 \%)$ & 0.761 & & \\
\hline Ventilator-associated pneumonia & $5(4.7 \%)$ & $5(14.3 \%)$ & 0.120 & & \\
\hline Primary bacteraemia & $15(14.2 \%)$ & $13(37.1 \%)$ & 0.006 & & \\
\hline Other $^{\mathrm{a}}$ & $6(5.7 \%)$ & $3(8.6 \%)$ & 0.690 & & \\
\hline SAPS II upon onset of infection & $36.1 \pm 10.1$ & $48.4 \pm 11.8$ & $<0.001$ & & \\
\hline SOFA score upon onset of infection & $6.5 \pm 3.0$ & $9.6 \pm 3.6$ & $<0.001$ & & \\
\hline Appropriate empiric treatment & $100(94.3 \%)$ & $22(62.9 \%)$ & $<0.001$ & 0.011 & $0.20(0.06-0.69)$ \\
\hline Beta-lactam-containing regimen & $91(85.8 \%)$ & $30(85.7 \%)$ & 1.000 & & \\
\hline Glycopeptide-containing regimen & $70(66.0 \%)$ & $21(60.0 \%)$ & 0.545 & & \\
\hline Linezolide-containing regimen & $32(30.2 \%)$ & $11(31.4 \%)$ & 1.000 & & \\
\hline Daptomycin-containing regimen & $6(5.7 \%)$ & $1(2.9 \%)$ & 0.681 & & \\
\hline Corticosteroid administration during infection & $55(51.9 \%)$ & $18(51.4 \%)$ & 1.000 & & \\
\hline Parenteral nutrition & $38(35.8 \%)$ & $13(37.1 \%)$ & 1.000 & & \\
\hline Enteral nutrition & $74(69.8 \%)$ & $17(48.6 \%)$ & 0.027 & & \\
\hline Acute kidney injury & $17(16.0 \%)$ & $21(60.0 \%)$ & $<0.001$ & - & - \\
\hline Hemodialysis & $6(5.7 \%)$ & $7(20.0 \%)$ & 0.018 & & \\
\hline Thrombopenia $\left(<100 \times 10^{9} / 1\right)$ & $15(14.2 \%)$ & $16(48.5 \%)$ & $<0.001$ & - & - \\
\hline \multicolumn{6}{|l|}{ Microbiologic data } \\
\hline \multicolumn{6}{|l|}{ Species } \\
\hline Coagulase negative staphylococci & $53(50.0 \%)$ & $16(45.7 \%)$ & 0.700 & & \\
\hline S. aureus & $15(14.2 \%)$ & $7(20.0 \%)$ & 0.426 & & \\
\hline Enterococci & $34(32.1 \%)$ & $12(34.3 \%)$ & 0.837 & & \\
\hline Streptococci & $4(3.8 \%)$ & $0(0.0 \%)$ & 0.572 & & \\
\hline
\end{tabular}

Resistance 
Table 1 (continued)

\begin{tabular}{|c|c|c|c|c|c|}
\hline \multirow[t]{2}{*}{ Characteristics } & \multicolumn{3}{|l|}{ Univariate analysis } & \multicolumn{2}{|c|}{ Multivariate analysis } \\
\hline & Survivors $(n=106)$ & Non-survivors $(n=35)$ & $P$ & $P$ & OR $(95 \% \mathrm{CI})$ \\
\hline Methicillin resistance ${ }^{\mathrm{b}}$ & $58(85.3 \%)$ & $17(73.9 \%)$ & 1.000 & & \\
\hline Vancomycin resistance ${ }^{c}$ & $7(20.0 \%)$ & $4(33.3 \%)$ & 0.435 & & \\
\hline Linezolid resistance $^{\mathrm{d}}$ & $19(35.8 \%)$ & $4(25.0 \%)$ & 0.550 & & \\
\hline
\end{tabular}

Data are number $(\%)$ of patients or mean \pm standard deviation

APACHE II: Acute Physiology and Chronic Health Evaluation II, SAPS II: Simplified Acute Physiology Score II, SOFA: Sequential Organ Failure Assessment

a Three nosocomial meningitis, three surgical site infections, two endocarditis, one septic arthritis

${ }^{\mathrm{b}}$ Among all staphylococci $(n=91)$

${ }^{\mathrm{c}}$ Among all enterococci $(n=46)$

${ }^{\mathrm{d}}$ Among coagulase negative staphylococci $(n=69)$

$24.8 \%$ (35 patients). Table 1 shows univariate and multivariate analyses of predictors of BSI fatality. Multivariate analysis revealed septic shock ( $P$ 0.039; OR 4.0, CI 1.1-10.9) as independent predictor of fatality, while appropriate empiric antimicrobial treatment $(P$ 0.011; OR 0.20, CI 0.06-0.69) and catheter-related BSI $(P$ 0.024; OR 0.28, CI 0.09-0.85) were identified as a predictor of good prognosis.

Twenty-three among the 69 coagulase-negative staphylococci were methicillin and linezolid-resistant, therefore, we have performed a secondary analysis for risk factors for development of bacteraemia by linezolid-resistant strains. Multivariate analysis revealed administration of linezolid (P0.015; OR 4.9, CI 1.4-18.1) as the only independent risk factor for development of bacteraemia by linezolid-resistant coagulase-negative staphylococci Table 2.

\section{Discussion}

During the study period, infections due to Gram-positive cocci accounted for $24.5 \%$ of all BSIs, with carbapenemaseproducing Gram-negative bacteria being the most prominent (55.0\%). In general, the incidence of BSIs independently of the pathogen isolated is high in our study (24.2\%) in comparison to the literature (7.8\% in EPIC II) [3]. A shift in BSI's epidemiology in Greek hospitals was observed in the last two decades towards predominance of Gram-negative bacteria, due to emergence and dissemination of very successful clones of carbapenemase-producing Gram-negative bacilli [5.6]. Even though in the EPIC II study infections due to Gramnegative bacteria predominated, the epidemiology of BSI varies widely between countries, with many showing a predominance of Gram-positive cocci [1, 6, 21].

As compared to carbapenemase-producing Gram-negative bacilli, fatality of BSIs due to Gram-positive cocci was lower $(24.8 \%)$, as previously shown [2]. The most consistent predictor of survival in the literature was administration of appropriate empiric antibiotic therapy $[1,22]$. In the present study, despite the high rate of multi-drug resistant pathogens (86; 61.0\%; 10 MRSA, 65 MR-CNS, 11 VRE), $86.5 \%$ of patients received appropriate empiric treatment. This high percentage can be explained by the fact that these pathogens are prevalent in the Greek healthcare system, leading to an empiric initiation of anti-Gram-positive antibiotics, such as glycopeptides (vancomycin or teicoplanin), linezolid, or daptomycin in all patients with a severe infection [5]. Glycopeptides were the preferred agent as empiric coverage in our cohort, with only 11 isolates $(8.7 \%)$ being resistant. In the EUROBACT study, vancomycin was also the most commonly used antibiotic with anti-Gram positive action, followed by linezolid and daptomycin [1]. Even though many studies have shown during the last decades an increase of vancomycin MIC among MRSA [23], a phenomenon known as MIC creep, our isolates had an $\mathrm{MIC} \leq 1 \mathrm{mg} / \mathrm{l}$, for which vancomycin remains the preferred agent. A previous Greek multicenter study showed a decrease of MIC among MRSA from 2008 to 2012, which was probably due to the reduction of vancomycin utilization in favor to newer therapeutic options, such as linezolid and daptomycin [8].

Another reason for the low fatality was the fact that Grampositive bacteria, as compared to carbapenemase-producing Gram-negative bacteria, were more commonly associated with CR-BSIs [24], and better clinical outcome due to easy and rapid source control by removing the infected catheter [1, 4, 21, 25]. In the present study, CR-BSIs accounted for more than half of BSIs, and can explain the fact that CNS predominated among Gram-positive cocci, since they have a propensity to colonize indwelling devices and subsequently provoke infection. Reinforcing strategies for prevention of CR-BSI are the following: training of medical personnel on antisepsis, introduction of checklist for CVC insertion, and education of nursing personnel for disinfecting techniques for inserted catheters [25]. 
Table 2 Univariate and multivariate analyses of risk factors for infection due to linezolid-resistant coagulase negative staphylococci

\begin{tabular}{|c|c|c|c|c|c|}
\hline \multirow[t]{2}{*}{ Characteristics } & \multicolumn{3}{|l|}{ Univariate analysis } & \multicolumn{2}{|c|}{ Multivariate analysis } \\
\hline & LS-CNS $(n=46)$ & LR-CNS $(n=23)$ & $P$ & $P$ & OR $(95 \% \mathrm{CI})$ \\
\hline \multicolumn{6}{|l|}{ Demographics } \\
\hline Age (years) & $58.0 \pm 16.6$ & $54.4 \pm 22.5$ & 0.660 & & \\
\hline Male gender & $34(73.9 \%)$ & $21(91.3 \%)$ & 0.119 & & \\
\hline \multicolumn{6}{|l|}{ Chronic diseases } \\
\hline Diabetes mellitus & $6(13.0 \%)$ & $3(13.0 \%)$ & 1.000 & & \\
\hline Chronic obstructive pulmonary disease & $3(6.5 \%)$ & $1(4.3 \%)$ & 1.000 & & \\
\hline Chronic heart failure & $5(10.9 \%)$ & $0(0.0 \%)$ & 0.161 & & \\
\hline Chronic kidney disease & $1(2.2 \%)$ & $0(0.0 \%)$ & 1.000 & & \\
\hline Malignancy (solid organ or haematologic) & $4(8.7 \%)$ & $2(8.7 \%)$ & 1.000 & & \\
\hline Immunosuppression & $1(2.2 \%)$ & $1(4.3 \%)$ & 1.000 & & \\
\hline Obesity & $14(30.4 \%)$ & $6(26.1 \%)$ & 0.784 & & \\
\hline Charlson comorbidity index & $3.4 \pm 2.7$ & $3.1 \pm 3.2$ & 0.575 & & \\
\hline \multicolumn{6}{|l|}{ Admission data } \\
\hline SAPS II upon admission & $38.8 \pm 12.8$ & $32.4 \pm 8.2$ & 0.058 & & \\
\hline SOFA score upon admission & $9.3 \pm 3.5$ & $7.4 \pm 2.4$ & 0.064 & & \\
\hline Prior surgery & $18(39.1 \%)$ & $10(43.5 \%)$ & 0.798 & & \\
\hline \multicolumn{6}{|l|}{ Prior antibiotic administration } \\
\hline Penicillins & $24(52.2 \%)$ & $11(47.8 \%)$ & 0.802 & & \\
\hline Cephalosporins & $6(13.0 \%)$ & $0(0.0 \%)$ & 0.168 & & \\
\hline Carbapenems & $34(73.9 \%)$ & $22(95.7 \%)$ & 0.047 & & \\
\hline Glycoptetides & $38(82.6 \%)$ & $19(82.6 \%)$ & 1.000 & & \\
\hline Linezolid & $8(17.4 \%)$ & $14(60.9 \%)$ & 0.001 & 0.015 & $4.9(1.4-18.1)$ \\
\hline Daptomycin & $0(0.0 \%)$ & $1(4.3 \%)$ & 0.333 & & \\
\hline Tigecycline & $1(2.2 \%)$ & $7(30.4 \%)$ & 0.001 & & \\
\hline Colistin & $10(21.7 \%)$ & $17(73.9 \%)$ & $<0.001$ & & \\
\hline Aminoglycosides & $15(32.6 \%)$ & $12(52.2 \%)$ & 0.128 & & \\
\hline Quinolones & $3(6.5 \%)$ & $1(4.3 \%)$ & 1.000 & & \\
\hline Number of antibiotics administered & $3.1 \pm 1.6$ & $4.8 \pm 2.0$ & 0.001 & - & - \\
\hline \multicolumn{6}{|l|}{ Infection data } \\
\hline Days at risk & $11.2 \pm 8.3$ & $16.5 \pm 10.1$ & 0.022 & - & - \\
\hline Septic shock & $14(30.4 \%)$ & $6(26.1 \%)$ & 0.784 & & \\
\hline Noradrenaline dose $(\mu \mathrm{g} / \mathrm{kg} / \mathrm{min})$ & $9.3 \pm 15.7$ & $6.3 \pm 13.8$ & 0.261 & & \\
\hline \multicolumn{6}{|l|}{ Source of infection } \\
\hline Catheter-related bateraemia & $39(84.8 \%)$ & $17(77.3 \%)$ & 0.505 & & \\
\hline Primary bacteraemia & $7(15.2 \%)$ & $5(22.7 \%)$ & & & \\
\hline SAPS II upon onset of infection & $39.7 \pm 12.7$ & $35.5 \pm 11.0$ & 0.239 & & \\
\hline SOFA score upon onset of infection & $6.5 \pm 3.5$ & $6.1 \pm 2.5$ & 0.890 & & \\
\hline Prior corticosteroid administration & $18(39.1 \%)$ & $12(52.2 \%)$ & 0.318 & & \\
\hline Prior parenteral nutrition & $14(30.2 \%)$ & $2(52.2 \%)$ & 0.114 & & \\
\hline Prior enteral nutrition & $28(60.9 \%)$ & $15(65.2 \%)$ & 0.796 & & \\
\hline Methicillin resistance & $43(93.5 \%)$ & $22(95.7 \%)$ & 1.000 & & \\
\hline
\end{tabular}

Data are number $(\%)$ of patients or mean \pm standard deviation

APACHE II, Acute Physiology and Chronic Health Evaluation II; CNS, coagulase negative staphylococci; LS, linezolid-susceptible; LR, linezolidresistant; SAPS II, Simplified Acute Physiology Score II; SOFA: Sequential Organ Failure Assessment

One-third of infections due to CNS were linezolid resistant (LR). Consistently with the literature, prior administration of linezolid was the only risk factor for development of infection by LR isolates [11, 12, 26]. Among patients with LR-CNS 
BSI, 39.1\% did not receive linezolid in the last 2 months prior to BSI development, indicating that such isolates disseminated to patients in nearby beds, as previously shown $[11,26]$. All LR $S$. epidermidis belonged to ST22 and carried both C2534T, T2504A; aforementioned ST and mutations were found in previous studies from our setting and other Greek and European hospitals underlying the success of that clone $[11,13,26]$. The efficacy of LR-CNS in disseminating and becoming endemic in different hospital wards, including those with low linezolid consumption, was shown in a Spanish university hospital. In that study, LR $S$. epidermidis belonged to ST2 and apart from G2576 T 23S rDNA mutation, they also carried a variety of mutations in the genes encoding L3 and L4 ribosomal proteins [27]. No isolate in the present study carried the transferable $c$ fr gene which encodes an rRNA methyltransferase; this gene has been detected in CNS, S. aureus and even enterococci, especially in central and north America [28].

Clones of vancomycin-resistant E. faecium found in the present study (ST117, ST17, ST203) represent previously found ones in Greece, belonging to the highly worldwide successful clonal complex 17 [29]. Epidemiology of ST types of MRSA strains represents the current Greek epidemiology with the invasion of the community-acquired ST80 clone in the healthcare system supplanting the previous nosocomial clone of ST239 [7, 30]. The four infections due to ST30 depict this clone's dissemination among patients and personnel of the ICU [31].

The present study has several limitations. First, this is a retrospective study in one ICU with high incidence of infections. Second, since a high rate of BSIs was related to CVC, and due to high rate of multidrug-resistant pathogens, our results may not be directly extrapolated to regions with lower incidence of CR-BSI or multidrug-resistant pathogens. No data on vancomycin's trough levels were included in our analysis since they were not routinely measured.

Gram-positive BSIs represented approximately one-fourth of all BSIs in a setting with endemic carbapenemaseproducing Gram-negative bacteria, justifying an empiric utilization of an anti-Gram-positive antibiotic. Even though most of them were multidrug-resistant, fatality was low, associated with CR-BSIs. Among CNS, LR isolates represented onethird of BSIs due to dissemination of ST22 S. epidermidis propagated by utilization of linezolid.

Funding information This study was supported by internal funds.

\section{Compliance with ethical standards}

Conflict of interest The authors declare that there are no conflicts of interest.

Ethical approval The study was approved by the Bioethics' Committee of the University General Hospital of Patras (No 434).

\section{References}

1. Tabah A, Koulenti D, Laupland K, Misset B, Valles J, Bruzzi de Carvalho F, Paiva JA, Cakar N, Ma X, Eggimann P, Antonelli M, Bonten MJ, Csomos A, Krueger WA, Mikstacki A, Lipman J, Depuydt P, Vesin A, Garrouste-Orgeas M, Zahar JR, Blot S, Carlet J, Brun-Buisson C, Martin C, Rello J, Dimopoulos G, Timsit JF (2012) Characteristics and determinants of outcome of hospital-acquired bloodstream infections in intensive care units: the EUROBACT International Cohort Study. Intensive Care Med 38: 1930-1945

2. Pouwels KB, Vansteelandt S, Batra R, Edgeworth JD, Smieszek T, Robotham JV (2018) Intensive care unit (ICU)-acquired bacteraemia and ICU mortality and discharge: addressing timevarying confounding using appropriate methodology. J Hosp Infect 99:42-47

3. Vincent JL, Rello J, Marshall J, Silva E, Anzueto A, Martin CD, Moreno R, Lipman J, Gomersall C, Sakr Y, Reinhart K, Investigators EIGo (2009) International study of the prevalence and outcomes of infection in intensive care units. JAMA 302: 2323-2329

4. Ziegler MJ, Pellegrini DC, Safdar N (2015) Attributable mortality of central line associated bloodstream infection: systematic review and meta-analysis. Infection 43:29-36

5. Kolonitsiou F, Papadimitriou-Olivgeris M, Spiliopoulou A, Stamouli V, Papakostas V, Apostolopoulou E, Panagiotopoulos C, Marangos M, Anastassiou ED, Christofidou M, Spiliopoulou I (2017) Trends of bloodstream infections in a university Greek hospital during a three-year period: incidence of multidrug-resistant bacteria and seasonality in gram-negative predominance. Pol J Microbiol 66:171-180

6. Orsi GB, Giuliano S, Franchi C, Ciorba V, Protano C, Giordano A, Rocco M, Venditti M (2015) Changed epidemiology of ICU acquired bloodstream infections over 12 years in an Italian teaching hospital. Minerva Anestesiol 81:980-988

7. Nikolaras GP, Papaparaskevas J, Samarkos M, Tzouvelekis LS, Psychogiou M, Pavlopoulou I, Goukos D, Polonyfi K, Pantazatou A, Deliolanis I, Smilakou S, Daikos GL (2019) Changes in the rates and population structure of methicillin-resistant Staphylococcus aureus (MRSA) from bloodstream infections: a single-centre experience (2000-2015). J Glob Antimicrob Resist 17:117-122

8. European Centre for Disease Prevention and Control (ECDC) (2018) Surveillance of antimicrobial resistance in Europe - annual report of the European Antimicrobial Resistance Surveillance Network (EARS-net) 2017. ECDC, Stockholm

9. Papadimitriou-Olivgeris M, Kolonitsiou F, Zerva L, Lebessi E, Koutsia C, Drougka E, Sarrou S, Giormezis N, Vourli S, Doudoulakakis A, Konsolakis C, Marangos M, Anastassiou ED, Petinaki E, Spiliopoulou I (2015) Activity of vancomycin, linezolid, and daptomycin against staphylococci and enterococci isolated in 5 Greek hospitals during a 5-year period (2008-2012). Diagn Microbiol Infect Dis 83:386-388

10. Karavasilis V, Zarkotou O, Panopoulou M, Kachrimanidou M, Themeli-Digalaki K, Stylianakis A, Gennimata V, Ntokou E, Stathopoulos C, Tsakris A, Pournaras S, Greek Study Group on Staphylococcal Linezolid R (2015) Wide dissemination of linezolid-resistant Staphylococcus epidermidis in Greece is associated with a linezolid-dependent ST22 clone. J Antimicrob Chemother 70:1625-1629

11. Papadimitriou-Olivgeris M, Giormezis N, Fligou F, Liakopoulos A, Marangos M, Anastassiou ED, Petinaki E, Filos KS, Spiliopoulou I (2013) Factors influencing linezolid-nonsusceptible coagulase-negative staphylococci dissemination among patients in the intensive care unit: a retrospective cohort study. Chemotherapy 59:420-426 
12. Wessels C, Strommenger B, Klare I, Bender J, Messler S, Mattner F, Krakau M, Werner G, Layer F (2018) Emergence and control of linezolid-resistant Staphylococcus epidermidis in an ICU of a German hospital. The J Antimicrob Chemother 73:1185-1193

13. Dortet L, Glaser P, Kassis-Chikhani N, Girlich D, Ichai P, Boudon M, Samuel D, Creton E, Imanci D, Bonnin R, Fortineau N, Naas T (2018) Long-lasting successful dissemination of resistance to oxazolidinones in MDR Staphylococcus epidermidis clinical isolates in a tertiary care hospital in France. J Antimicrob Chemother 73:41-51

14. Horan TC, Andrus M, Dudeck MA (2008) CDC/NHSN surveillance definition of health care-associated infection and criteria for specific types of infections in the acute care setting. Am J Infect Control 36:309-332

15. Singer M, Deutschman CS, Seymour CW, Shankar-Hari M, Annane D, Bauer M, Bellomo R, Bernard GR, Chiche JD, Coopersmith CM, Hotchkiss RS, Levy MM, Marshall JC, Martin GS, Opal SM, Rubenfeld GD, van der Poll T, Vincent JL, Angus DC (2016) The third international consensus definitions for sepsis and septic shock (Sepsis-3). JAMA 315:801-810

16. Bell J, Turnidge J, Coombs G, O'Brien F (1998) Emergence and epidemiology of vancomycin-resistant enterococci in Australia. Commun Dis Intell 22:249-252

17. Petinaki E, Arvaniti A, Dimitracopoulos G, Spiliopoulou I (2001) Detection of mecA, mecR1 and mecI genes among clinical isolates of methicillin-resistant staphylococci by combined polymerase chain reactions. J Antimicrob Chemother 47:297-304

18. Mendes RE, Deshpande LM, Castanheira M, DiPersio J, Saubolle MA, Jones RN (2008) First report of $c f r$-mediated resistance to linezolid in human staphylococcal clinical isolates recovered in the United States. Antimicrob Agents Chemother 52:2244-2246

19. Liakopoulos A, Neocleous C, Klapsa D, Kanellopoulou M, Spiliopoulou I, Mathiopoulos KD, Papafrangas E, Petinaki E (2009) A T2504A mutation in the 23S rRNA gene responsible for high-level resistance to linezolid of Staphylococcus epidermidis. J Antimicrob Chemother 64:206-207

20. Wong A, Reddy SP, Smyth DS, Aguero-Rosenfeld ME, Sakoulas G, Robinson DA (2010) Polyphyletic emergence of linezolidresistant staphylococci in the United States. Antimicrob Agents Chemother 54:742-748

21. Adrie C, Garrouste-Orgeas M, Ibn Essaied W, Schwebel C, Darmon M, Mourvillier B, Ruckly S, Dumenil AS, Kallel H, Argaud L, Marcotte G, Barbier F, Laurent V, Goldgran-Toledano D, Clec'h C, Azoulay E, Souweine B, Timsit JF, OUTCOMEREA Study Group (2017) Attributable mortality of ICU-acquired bloodstream infections: impact of the source, causative micro-organism, resistance profile and antimicrobial therapy. J Inf Secur 74:131-141

22. Brooks D, Polubothu P, Young D, Booth MG, Smith A (2018) Sepsis caused by bloodstream infection in patients in the intensive care unit: the impact of inactive empiric antimicrobial therapy on outcome. J Hosp Infect 98:369-374
23. Sader HS, Fey PD, Limaye AP, Madinger N, Pankey G, Rahal J, Rybak MJ, Snydman DR, Steed LL, Waites K, Jones RN (2009) Evaluation of vancomycin and daptomycin potency trends (MIC creep) against methicillin-resistant Staphylococcus aureus isolates collected in nine U.S. medical centers from 2002 to 2006. Antimicrob Agents Chemother 53:4127-4132

24. Papadimitriou-Olivgeris M, Fligou F, Bartzavali C, Zotou A, Spyropoulou A, Koutsileou K, Vamvakopoulou S, Sioulas N, Karamouzos V, Anastassiou ED, Spiliopoulou I, Christofidou M, Marangos M (2017) Carbapenemase-producing Klebsiella pneumoniae bloodstream infection in critically ill patients: risk factors and predictors of mortality. Eur J Clin Microbiol Infect Dis 36: $1125-1131$

25. Lin KY, Cheng A, Chang YC, Hung MC, Wang JT, Sheng WH, Hseuh PR, Chen YC, Chang SC (2017) Central line-associated bloodstream infections among critically-ill patients in the era of bundle care. J Microbiol Immunol Infect 50:339-348

26. Trevino M, Martinez-Lamas L, Romero-Jung PA, Giraldez JM, Alvarez-Escudero J, Regueiro BJ (2009) Endemic linezolidresistant Staphylococcus epidermidis in a critical care unit. Eur $\mathbf{J}$ Clin Microbiol Infect Dis 28:527-533

27. Rodríguez-Lucas C, Rodicio MR, Càmara J, Domínguez MÁ, Alaguero M, Fernández J (2019) Long-term endemic situation caused by a linezolid- and methicillin-resistant clone of Staphylococcus epidermidis in a tertiary hospital. J Hosp Infect pii S0195-6701(19):30448-30447

28. Mendes RE, Deshpande LM, Jones RN (2014) Linezolid update: stable in vitro activity following more than a decade of clinical use and summary of associated resistance mechanisms. Drug Resist Updat 17:1-12

29. Papadimitriou-Olivgeris M, Drougka E, Fligou F, Kolonitsiou F, Liakopoulos A, Dodou V, Anastassiou ED, Petinaki E, Marangos M, Filos KS, Spiliopoulou I (2014) Risk factors for enterococcal infection and colonization by vancomycin-resistant enterococci in critically ill patients. Infection 42:1013-1022

30. Drougka E, Foka A, Liakopoulos A, Doudoulakakis A, Jelastopulu E, Chini V, Spiliopoulou A, Levidiotou S, Panagea T, Vogiatzi A, Lebessi E, Petinaki E, Spiliopoulou I (2014) A 12-year survey of methicillin-resistant Staphylococcus aureus infections in Greece: ST80-IV epidemic? Clin Microbiol Infect 20:O796-O803

31. Papadimitriou-Olivgeris M, Drougka E, Fligou F, Dodou V, Kolonitsiou F, Filos KS, Anastassiou ED, Petinaki E, Marangos M, Spiliopoulou I (2017) Spread of tst-positive Staphylococcus aureus strains belonging to ST30 clone among patients and healthcare workers in two intensive care units. Toxins (Basel) 9 . Pii: E270

Publisher's note Springer Nature remains neutral with regard to jurisdictional claims in published maps and institutional affiliations. 